\title{
The Development of the 'Straight Rod Type' of Lactobacillus bifidus
}

\author{
BY H. G. GYLLENBERG \\ Department of Microbiology, University of Helsinki, Finland
}

\begin{abstract}
SUMMARY: Microscopical examinations of several Lactobacillus bifidus strains have shown that the 'bifid' morphology of the cells, which seems to predominate in vivo, is readily changed on subcultivation in different media in vitro. At first highly branched and larger forms occur, and from these mycelial branched filaments develop. The mycelial cells may swell, in which case intensely staining coccoid granules can be detected in the cells. Ultimately, the filaments break up, and give rise to the development of regular short straight rods. Obviously these straight rods appear from the coccoid granules.
\end{abstract}

It is well known that Lactobacillus bifidus occurs as two different morphological types: a 'bifid' type occurring as branched cells, and a 'straight rod' type showing regular straight rods (e.g. Norris, Flanders, Tomarelli \& György, 1950). In the intestines of young infants the bifid form may predominate, but this morphological character is readily lost in vitro with a change to the straight rod type. The change is reported to be irreversible (Norris et al. 1950; Norris, De Sipin, Zilliken, Harvey \& György, 1954), and probably instantaneous (Norris et al. 1950). The change takes place most frequently in complex media containing cow's milk or vegetable extracts. Some authors have succeeded in maintaining their strains unchanged in chemically defined media (e.g. György, 1953; Petuely \& Lynau, 1954). Most of the recent studies of L. bifidus have dealt with its nutrition, and in this connexion attention has been drawn to the abundance of this bacterium in the intestines of infants fed on human milk. Hence the major interest has been directed to the bifid type, and the morphological variation has been investigated only in attempts to avoid it. Observations made during the routine microscopical control of bifid cultures led the present author to a more extensive investigation of the morphological variation of $L$. bifidus. This seemed to deserve special attention since certain features showed a resemblance to the morphogenesis described earlier as characteristic of some systematically related bacteria, e.g. polymorphic corynebacteria.

\section{METHODS}

All the strains investigated were isolated from the faeces of breast-fed infants. Isolation was carried out according to ordinary techniques; single-cell cultures were not investigated. All isolates were obtained from high dilutions (from tubes or plates where only 1-10 colonies had grown). A nutrient agar prepared according to Hassinen, Durbin, Tomarelli \& Bernhart (1951) was usually employed for isolation. This medium seems to permit slight growth of Lacto- 
bacillus bifidus, at least in the isolation passage, but as reported by Hassinen et al. (1951), and as found by the present author, other intestinal bacteria may fail to grow in it. An additional spreading of the cultures was carried out, and re-isolates were taken from suitable high dilutions.

The cultures were maintained in liquid media or as stabs in the Hassinen et al. nutrient agar. The media used were prepared according to Hassinen $e t$ al. (1951), György (1953), and Gyllenberg, Rossander \& Roine (1953). Tomato agar (Difco, Kulp) was also used for stabs. The stock cultures were renewed once or twice each week.

The smears were stained unfixed with Hucker's crystal violet or Ziehl's carbol fuchsin. Phase-contrast equipment was used for the examination of unstained smears.

\section{RESULTS}

The cell shape of primary cultures was quite typical. The rods were short (2-4 $\mu$. long), the ends were pointed or cleft, and curved rods were abundant. Manifold branchings and mycelial forms were not seen. This cell shape (referred to below as the bifid type), which obviously predominates in vivo, is illustrated in Pl. 1, fig. 1. On continued cultivation in vitro, the original bifid shape disappeared in a few subcultures. The size of the organism increased (4-8 $\mu$. long) and manifold branching was regularly encountered (Pl. 1, fig. 2). Such organisms (referred to as the 'branched' type) were often swollen, especially in old cultures, in which they stained heterogeneously and showed chains of deeply stained granules. When cultivation was continued, still larger branched mycelial filaments are found (Pl. 1, fig. 3). It seems that these forms developed especially when the cultures grew very rapidly.

Cultures with organisms in the branched state were maintained unchanged through several subcultures, although the cell size and the branching frequency were highly variable. Ultimately, however, a rapid change to straight rods took place; these rods were regular and short, and 1-2 $\mu$. long (Pl. 1, fig. 4).

It seemed that the short rods developed from the mycelial filaments. In swollen filaments chains of granules occurred (Pl. 1, fig. 5), as already mentioned. In some cultures, however, the mycelial filaments were abruptly broken up, and only 'granule chains' remained. These chains were often branched, and showed arrangements similar to those of the granules in the original intact filaments (Pl. 1, fig. 6). Figures 5 and 6 of $\mathrm{Pl} .1$ represent the appearance of samples from the same culture, taken at 20 and $23 \mathrm{hr}$., respectively, i.e. at an interval of $3 \mathrm{hr}$. Pl. 1, fig. 7, also illustrates this phenomenon: (a) represents a mycelial filament in an early stage of breakdown; $(b)$ shows branched chains of short rods. The short straight rods which develop in this way rapidly lose their ability to form chains, and they then occur in irregular masses (cf. Pl. 1, fig. 4). It is possible that the straight rods under certain conditions may become branched or bifid, but the author has not succeeded in obtaining definite evidence on this point.

The observations described above show that the appearance of the straight rods is a result of a gradual development, although the final phase seems to 
proceed very rapidly. It can be concluded that the tendency to develop branched mycelial filaments characterizes the first step towards the straight rod type, since the straight rods obviously arise from granules which occur in the filaments. The branched filaments are broken up into short rods in a similar way to that described for the transformation of filamentous cells of corynebacteria to coccoid forms (cf. Conn \& Dimmick, 1947). It can be supposed, therefore, that the granules in Lactobacillus bifidus correspond to the beads or 'arthrospores' which occur in certain corynebacteria. Should this prove to be the case, the relationship of $L$. bifidus to the corynebacteria, which, as stated by some authors (e.g. Olsen, 1949), may be a very close one, needs further explanation.

Primary bifid Lactobacillus bifidus cultures require good anaerobic conditions for growth, whereas the branched cultures are microaerophilic, and the straight rod cultures are usually capable of aerobic growth. Accordingly, it seems possible that the first morphological change (from bifid to branched) may be induced under conditions where the oxidation-reduction potential is not low enough to permit the bifid type to maintain its characteristic behaviour. Petuely \& Lynau (1954) reported that $L$. bifidus can be maintained in the bifid state when the media are richly supplied with ascorbic acid. According to these authors, other cell shapes may indicate that degeneration is taking place under unfavourable conditions. It seems more probable, however, that these changes are due to true morphogenesis, since they take place under conditions where the generating new types seem to grow vigorously.

Single-cell cultures were not studied in the present investigation. This fact may introduce some measure of uncertainty. However, the phenomena described were observed with several different cultures, and as pointed out earlier, it may be assumed that the cultures studied were pure.

\section{REFERENCES}

ConN, H. J. \& Dimmick, I. (1947). Soil bacteria similar in morphology to Mycobacterium and Corynebacterium. J. Bact. 54, 291.

Gyllenderg, H., Rossander, M. \& Roine, P. (1953). A strain of Lactobacillus bifidus which requires strepogenin. J. gen. Microbiol. 9, 190.

GyörGy, P. (1953). A hitherto unrecognized biochemical difference between human milk and cow's milk. Pediatrics, 11, 98.

Hassinen, J. B., Durbin, G. T., Tomarelli, R. M. \& Bernhart, F. W. (1951). The minimal nutritional requirements of Lactobacillus bifidus. J. Bact. 62, 771 .

Norris, R. F., Flanders, T., Tomarelli, R. M. \& György, P. (1950). The isolation and cultivation of Lactobacillus bifidus. A comparison of branched and unbranched strains. J. Bact. 60, 681.

Norris, R. F., De Sipin, M., Zilliken, F. W., Harvey, S. \& György, P. (1954). Occurrence of mucoid variants of Lactobacillus bifidus. Demonstration of extracellular and intracellular polysaccharide. J. Bact. 67, 159.

Olsen, E. (1949). Studies on the Intestinal Flora of Infants, p. 147. Copenhagen: Ejnar Munksgaard.

Petuely, F. \& Lynau, V. (1954). Ein einfacher vollsyntetischer Optimalnährboden für den Lactobacillus bifidus. Über die Bedeutung der Ascorbinsäure für das Wachstum des Lactobacillus bifidus. Biochem. Z. 326, 62. 
Journal of General Microbiology, Vol. 13, No. 2
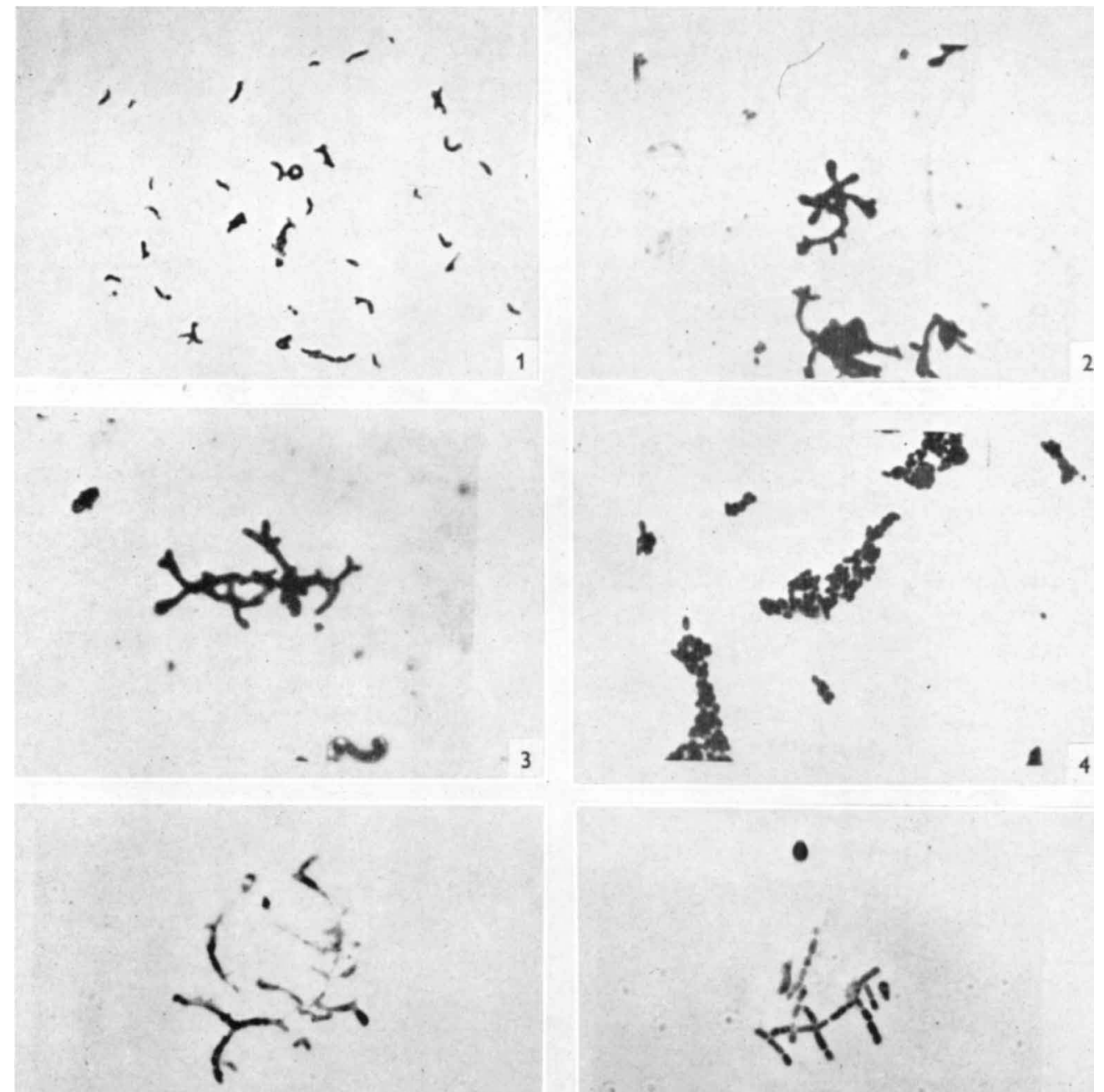

5

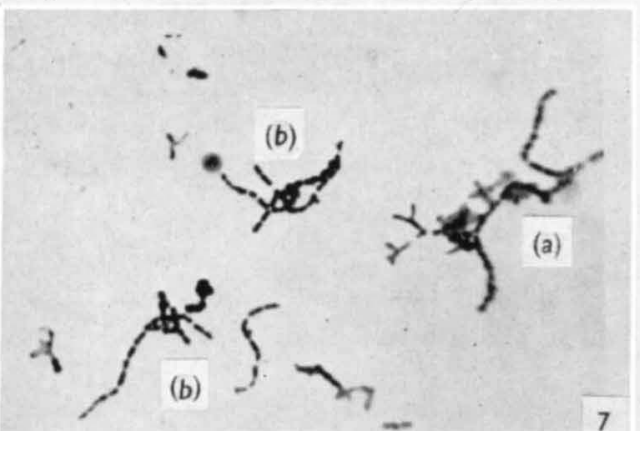

H. G. Gyllenberg-Morphology of Lactoracillues bifinus. Plate 1 


\section{EXPLANATION OF PLATE}

Fig. 1. Primary agar shake culture. Medium according to Hassinen et al. Age: $r 2 \mathrm{hr}$; $\times 1000$; crystal violet.

Fig. 2. Subcultured in vitro for 6 weeks. Tomato agar stab. Age: $72 \mathrm{hr}$; $\times 1000$; crystal violet.

Fig. 3. Subcultured in vitro for 10 weeks. Liquid medium according to György. Age : $48 \mathrm{hr}$; $\times 1000$; carbol fuchsin.

Fig. 4. Subcultured in vitro for 10 weeks. Tomato agar stab. Age: $48 \mathrm{hr}$.; $\times 1000$; carbol fuchsin.

Fig. 5. Subcultured in vitro for 12 weeks. Liquid medium according to Gyllenberg et al. Age $20 \mathrm{hr}$; $\times 1000$; phase contrast.

Fig. 6. Subcultured in vitro for 12 weeks. Liquid medium according to Gyllenberg et al. Age $23 \mathrm{hr}$; $\times 1000$; phase contrast.

Fig. 7. Subcultured in vitro for 10 weeks. Tomato agar stab. Age $48 \mathrm{hr}$; $\times 1000$; carbol fuchsin. (a) mycelial filament in an early stage of breakdown; $(b)$ branched chains of short rods.

(Received 9 May 1955) 